\title{
Specialist assessment clinic for pervasive developmental disorders
}

\author{
Niall Falls
}

\begin{abstract}
Aims and method The Joint Committee on Higher Psychiatric Training lists the ability to carry out a thorough clinical assessment, including physical and mental state examination, as one of the essential core skills in child and adolescent psychiatry. Experience of the assessment of comparatively rare disorders may depend upon the organisation of regional services, as well as good working relationships between teams willing to involve the trainee.

Results This paper describes a six-month attachment to the first multi-disciplinary Specialist Assessment Clinic for Pervasive Developmental Disorders to be created in Northern Ireland. Assessments are multi-dimensional and multi-professional. Attachment to this specialist clinic has become a valuable resource, with demand exceeding availability of places.

Clinical implications The pervasive developmental disorders are characterised by onset before 36 months, qualitative impairments in social interaction and communication (both verbal and non-verbal), and a pattern of repetitive or stereotyped activities or interests (DSM-IV). Diagnostic criteria for these disorders have broadened since the introduction of DSM-IV and ICD-10. For example, both have now agreed the validity of Asperger's syndrome, featuring difficulties in social interaction, restricted and repetitive areas of interest, without clinically significant impairment of intelligence or language development.
\end{abstract}

The pervasive developmental disorders are characterised by onset before 36 months, qualitative impairments in social interaction and communication (both verbal and nonverbal) and a pattern of repetitive or stereotyped activities or interests (DSM-IV). Diagnostic criteria for these disorders have broadened since the introduction of DSM-IV (American Psychiatric Association, 1994) and ICD-10 (World Health Organization, 1992). For example, both have now agreed the validity of Asperger's Syndrome, featuring difficulties in social interaction, restricted and repetitive areas of interest, without clinically signifi- cant impairment of intelligence or language development.

\section{Prevalence rates}

Early epidemiological study of 'pure autism', yielded prevalence figures of 2-5/10 000 (Wing \& Gould, 1979). Considering the complete autistic spectrum, Wing (1993) estimates figures to be as high as 47/10 000. Extending this approach, the National Autistic Society (1997) recently published figures which they say include those with subtle forms of difficulty on the autistic spectrum. They report that 91 in every 10000 have some form of the disorder. amounting to around 518000 children and adults in the UK.

\section{Clinic format}

The assessment clinic is held once fortnightly in a large urban health centre, the area headquarters for many community services. It is staffed by a consultant clinical psychologist and assistant psychologist, a specialist speech and language therapist, a senior clinical medical officer (SCMO) and, for approximately the past 12 months, a senior registrar in child and adolescent psychiatry.

Referrals come from a wide range of sources, and are considered without age limit. Most commonly referrals come via the SCMO, or other team members' individual contact, but referrals are also received from adult and child and adolescent psychiatrists, clinical psychologists, general practitioners and speech therapists.

Each clinic begins with a team briefing. Notes and reports are reviewed, and any previous contacts discussed. The team splits into two units for the assessment, each spending half 
the day with parents and half with the person referred.

A detailed developmental history is taken from both parents (when available) by one or more of the team members. In doing so, both the Childhood Autism Rating Scale (CARS), and structured interviews designed by Stone \& Hogan (1993), are used as templates. Although comprehensive, the CARS alone may not be sensitive enough to detect the more subtle manifestations of some autistic disorders. DSM-IV and ICD-10 criteria are considered in diagnosis. In many cases, the CARS will be rerated using the parental history, information from the Stone \& Hogan questionnaires and from information gathered at a nursery or school observation. It is the team's experience that depending upon the family's stage of acceptance and age of the young person, parents may sometimes under-report symptoms.

While parents are being interviewed, the young person (as is usually the case) is beginning a formal assessment in an adjoining room. The two rooms are separated by a one-way screen, and parents can observe and comment on their child's progress. Depending on the subject's age and developmental level, one of several assessment tools may be used. Typically, in the first session, a Psycho-Educational Profile-Revised (PEP-R; Schopler et al, 1986) is carried out by the specialist speech and language therapist. An observer records details of social interaction, verbal and non-verbal communication and behaviour throughout the day. Designed for those with a developmental age in the range six months to seven years, this assessment gauges developmental attainment across several parameters, including comprehension, constructional tasks and coordination, as well as behavioural responses to various stimuli. The tester can identify areas of ability, delay and also 'emerging' scores, denoting areas which with the appropriate help could show improvement.

Following a working lunch, where the morning's history and assessments are reviewed, the two teams change positions for the second session. Psychometrics are carried out by the consultant psychologist or assistant, using the Merrill-Palmer (Stutsman, 1948) for pre-verbal children, the Wechsler Preschool and Primary Scale of Intelligence (Wechsler, 1990), Wechsler Intelligence Scale for Children (Wechsler, 1992), or Wechsler Adult Intelligence Scale (Revised) (Wechsler, 1986) as indicated. Meanwhile, the findings from the PEP-R and any previous assessment or observation are being corroborated with the family.

The day finishes with a team meeting to share all relevant findings, with a feed-back session for the family. A verbal summary, and where possible, initial impressions regarding diagnosis, are given, and any immediate questions addressed. The assessment may continue with one or more observation sessions, with a particular emphasis on examining peer relationships in a school or nursery setting. The implications of a written report are discussed. and how this might influence the future provision of education.

A detailed report of the team's assessment is then forwarded to the referrer, the family and, if indicated, the education authority. A review appointment is given for one week's time.

\section{What are the advantages to working in this setting?}

There are several obvious benefits, to staff and families, of a clinic dealing only with pervasive developmental disorders. First, families undergo an intensive and multi-disciplinary assessment. which might otherwise entail a series of appointments, with each professional, in various settings. The family will typically have a verbal summary of the assessment that day.

For the team, this clinic provides a regular forum for working with colleagues with a common interest. As awareness of the clinic grows, the increasing referral base ensures a demand for assessments on a group of patients, who share similar areas of difficulty, although with subtle differences. This constant challenge has built up a wealth of experience in this team which benefits families and trainees alike.

\section{The clinic as a training facility}

Within the clinic setting, the trainee gains from regular contact with individuals presenting such variation in autistic deficits. The chance to observe developmental and psychometric assessments may be the first for many trainees. Outside the clinic, the team encourages followup of patients into the educational setting. liaising with nursery and special needs teachers. Here, often elaborate and innovative strategies are devised to help sufferers and their families cope with their very individual difficulties.

One such approach is the TEACCH (Treatment and Education of Autistic Communication and related handicapped Children) programme, which originated in North Carolina in the 1960 s (Schopler et al, 1984). Although conceived as a process through which professionals and parents coworked the assessment and management of autistic difficulties, the term has become a byword for methods of educating, communicating with, and structuring the life of a person with such problems. Because of this local team's 
advocacy of the TEACCH methods, there is now an intensive five-day practical course and workshop held annually in Northern Ireland. This is led jointly by the directors of Division TEACCH, with a consultant clinical psychologist and specialist speech and language therapist from the multi-disciplinary clinic, who are now accredited trainers for the techniques. At this course, families using TEACCH methods discuss their experiences.

\section{Acknowledgement}

I wish to thank Ms E. Sherrard, Consultant Clinical Psychologist, for her invaluable assistance in preparing this report.

\section{References}

AMERICAN PSyChiatric Association (1994) Diagnostic and Statistical Manual of Mental Disorders (4th edn) (DSMIV). Washington, DC: APA.

NATIONAL AUTISTIC SOCIETY (1997) New statistics on the autistic spectrum. Communication, Spring, 3.

SCHOPLER, E., MESiBOV, G. B., ShiGley, R. H., et al (1984) Helping autistic children through their parents. The TEACCH model. In The Effects of Autism on The Family. (eds E. Schopler \& G. Mesibov), pp. 65-81. New York: Plenum Publishing Corporation.

-. REICHLER, R. J. \& RENNER, B. R. (1986) The Childhood Autism Rating Scale (CARS) for Diagnostic Screening and Classification of Autism. New York: Irvington.
-, - BASHFord, A., et al (1990) Psychoeducational Profile Revised. Austin, TX: Pro-Ed.

Stone, W. L. \& HOGAN, K. L. (1993) A structured parent interview for identifying young children with autism. Journal of Autism and Developmental Disorders, 4. 639-652.

STUTSMAN, R. (1948) Guide for administering the MerrillPalmer Scale of Mental Tests. In Mental Measurement of Preschool Children (ed. L. M. Treman), pp. 139-262. New York: Harcourt Brace.

WECHSLER, D. (1986) Manual for the Wechsler Adult Intelligence Scale-Revised. (UK edn). Sidcup: Psychological Corporation.

- (1990) Manual for the Wechsler Preschool and Primary Scale of Intelligence Revised (British amendments). Sidcup: Psychological Corporation.

- (1992) Manual for the Wechsler Intelligence Scale for Children (3rd UK edn). (WISC-III UK). Sidcup: Psychological Corporation.

WING. L. (1993) The definition and prevalence of autism: a review. European Child and Adolescent Psychiatry, 2. 61-74.

- \& GouLD, J. (1979) Severe impairments of social interaction and associated abnormalities in children: Epidemiology and classification. Journal of Autism and Childhood Schizophrenia, 9, 11-29.

WORLD HEALTH ORGANIZATION (1992) The Tenth Revision of the International Classification of Diseases and Related Health Problems (ICD-10). Geneva: WHO.

Niall Falls, Senior Registrar in Child and Adolescent Psychiatry, Young People's Centre, 10 College Gardens, Belfast BT9 6BQ

\section{NEW FROM GASKELL}

\section{FOCUS on Clinical Audit in Child and Adolescent Mental Health Services}

\section{Emma Hardman and Carol Joughin}

FOCUS on Clinical Audit in Child and Adolescent Mental Health Services aims to 'demystify' the process of clinical audit for those working in child and adolescent mental health services. It provides a step-by-step guide to clinical audit followed by examples of clinical audit projects undertaken in child and adolescent mental health services across Great Britain. While recognising the complexity and challenges which are particular to this specialty, it provides professionals with a pragmatic yet rigorous guide to clinical audit.

This book was developed with the help of many clinicians within CAMHS who gave their time and support in providing real examples of clinical audit projects.

READERSHIP:

- child and adolescent psychiatrists, clinical psychologists, nurses, occupational therapists, education/training establishments and managers of CAMHS services

- $\quad$ audit departments, paediatricians and commissioners

November 1998, £18.00, 144pp approx, Paperback, ISBN 1901242234

Royal College of Psychiatrists, 17 Belgrave SQuare, London SW1X 8PG TEL: +44 (0) 171235 2351, EXT 146 FAX: +44 (0) 1712451231 http://www.rcpsych.ac.uk 